OPEN ACCESS

Edited by:

Crochan John O'Sullivan,

Triemli Hospital, Switzerland

Reviewed by:

Augusto D'Onofrio

Università degli Studi di Padova, Italy

Ozan Demir,

San Raffaele Hospital (IRCCS), Italy

${ }^{*}$ Correspondence:

Rajiv Das

rajiv.das@nuth.nhs.uk

Rishi Puri

purir@ccf.org

Specialty section:

This article was submitted to

Structural Interventional Cardiology,

a section of the journal

Frontiers in Cardiovascular Medicine

Received: 28 March 2018

Accepted: 25 June 2018

Published: 19 July 2018

Citation:

Das $R$ and Puri $R$ (2018) Transcatheter Treatment of Bicuspid Aortic Valve

Disease: Imaging and Interventional

Considerations.

Front. Cardiovasc. Med. 5:91

doi: 10.3389/fcvm.2018.00091

\section{Transcatheter Treatment of Bicuspid Aortic Valve Disease: Imaging and Interventional Considerations}

\author{
Rajiv Das ${ }^{1 *}$ and Rishi Puri ${ }^{2 *}$ \\ ${ }^{1}$ Freeman Hospital, Newcastle upon Tyne, United Kingdom, ${ }^{2}$ Department of Cardiovascular Medicine, Cleveland Clinic, \\ Cleveland, $\mathrm{OH}$, United States
}

Patients with bicuspid aortic valve disease have systematically been excluded from large randomized clinical trials investigating transcatheter aortic valve implantation (TAVI) due to their younger age, lower surgical risk and complex aortic anatomy. The asymmetric nature of the bicuspid valve orifice often accompanied by heavy regional calcification has led to concerns regarding valve positioning and expansion. Bicuspid aortic valve disease patients are at heightened risk of TAVI-related complications including coronary occlusion, aortic dissection and annular rupture, as well as the known risks of progressive aortopathy in these patients. These unique anatomical characteristics pose challenges for TAVI operators. However, with recent and ongoing refinements in implantation technique, improvements in pre-procedural imaging and iterations in device design, TAVI is emerging as a safe and feasible treatment option in this population. Paravalvular aortic regurgitation and high pacemaker rates have been the Achilles Heel for TAVI in bicuspid valve patients, yet newer generation devices are yielding promising results. Further studies are required before TAVI ultimately emerges as a viable option in low and intermediate surgical-risk patients with bicuspid valve disease. This review comprehensively summarizes the epidemiology, pathology and current evidence for TAVI in patients with bicuspid aortic valve disease. We also outline some practical tips for performing TAVI in these patients.

Keywords: TAVI, bicuspid valve disease, CT, treatment, bicuspid aortic valve

\section{INTRODUCTION}

The transcatheter aortic valve implantation (TAVI) revolution for severe tricuspid aortic valve stenosis (AS) is well-recognized as an alternative to surgical aortic valve replacement (SAVR) for severe aortic stenosis. This has been established in the randomized clinical trials for balloon-expandable and self-expanding valves (1-4). TAVI is now regarded as the standard of care for patients with severe symptomatic AS that are considered inoperable or in patients at high surgical risk. More recently randomized clinical trials have shown non-inferiority when TAVI has been compared with SAVR in patients at intermediate or low surgical risk (5-7). Bicuspid aortic valve (BAV) has largely been excluded from seminal randomized clinical trials involving TAVI. This was due to concerns about (i) valve positioning and expansion due to the asymmetrical nature of the leaflets and heavy calcification leading to severe paravalvular leak (PVL), (ii) aortic annulus rupture and risk of coronary occlusion, (iii) concomitant aortopathy associated with BAV increasing 
the risk of spontaneous and iatrogenic aortic dissection and rupture, and (iv) concerns regarding the long-term durability of Transcatheter Heart Valves (THV), particularly in a younger BAV population. There is clear data on the safety and efficacy of TAVI in patients with tricuspid valve severe AS (1-10), and despite encouraging data from registries including BAV disease patients (11-14), TAVI has yet to establish itself in this patient cohort.

This review summarizes the evidence for TAVI in bicuspid aortic valve disease, the role of multi-slice computed tomography (MSCT) to aid procedural planning, and technical considerations to undertake when performing TAVI in BAV.

\section{EPIDEMIOLOGY}

BAV disease is a common congenital cardiac abnormality seen in adults and is frequently associated with AS (15). The estimated incidence of bicuspid aortic valves is $0.4-2.25 \%$ in the general population. The most frequent complication of BAV is $\mathrm{AS}$, often requiring aortic valve replacement surgery. BAV is commonly associated with aortopathy leading to asymptomatic dilatation of the ascending aorta in the initial stages followed by aneurysm formation of the aorta and the potential lifethreatening complication of aortic dissection (16-20). In a large population based study involving nearly 200 patients with a mean follow-up of 15 years, $13 \%$ developed severe AS requiring SAVR. In this cohort of patients, the main indication for surgery was severe AS; performed at a younger age group compared with the general population (21).

Registry data has shown that $37 \%$ of BAV patients have moderate-to-severe AS at the time of their initial echocardiogram (22). The prevalence of bicuspid aortic valve disease in patients undergoing surgical aortic valve replacement has been reported to be as high as $50 \%$ in some surgical series, $27.5 \%$ amongst octogenarians, and up to $41.7 \%$ of septuagenarians (23). In an Asian transcatheter aortic valve implantation (TAVI) population, BAV has been reported in upto $50 \%$, potentially posing unique challenges for percutaneous treatment options in the Asian landscape (24).

\section{PATHOLOGY}

BAV disease is frequently associated with valvular stenosis, valvular regurgitation, aortic coarctation, aortic dilatation, aneurysms, and dissection. It is essential that pre-procedural imaging assesses the thoracic aorta in BAV patients. Aortic root dilatation occurs in $50-60 \%$ of patients with a normally functioning bicuspid valve, increasing the risk of aortic dissection nine-fold (25). The etiology of ascending aortic dilatation may be due to genetic and hemodynamic factors that affect the aortic wall elasticity and strength. Genetic mutations in smooth muscle cells $\alpha$ actin (ACTA2) and transforming growth factor $\beta$ receptor (TGFBR1 and TGFBR2) have been linked with aortopathy in BAV disease (26). A genetic link between aortic dilatation and BAV can be substantiated by the fact there is greater incidence of aortopathy in first degree relatives with BAV disease, and not infrequently we see progressive aortic root dilatation in patients post SAVR with BAV disease (27).

Abnormalities in wall shear stress can arise due to the asymmetrical nature of the orifice in BAV patients. Studies using flow-sensitive MRI and four-dimensional (4D) cardiovascular MRI have looked at abnormalities in wall shear stress and flow patterns in the aortic wall for different BAV fusion patterns, which in turn has been linked with adverse remodeling within the aortic root wall $(28,29)$. The right and left cusp fusion variant of BAV is associated with asymmetrically elevated wall shear stress in the ascending aorta $(30,31)$. Phenotypic variations in BAV fusion patterns may need to be considered when assessing patients, especially if TAVI is to be extended to low-risk patients. As highlighted certain BAV fusion patterns are predictors of increased wall shear stress and aortic root dilatation (Figure 1).

\section{CLASSIFICATION SYSTEMS FOR BICUSPID AORTIC VALVE DISEASE}

Different classification systems exist for the varying BAV morphologies; based on the presence and characteristics of the raphe, commissural position, description of the cusp and its size and the aortic sinus characteristics $(15,21)$. The most widely used classification is by Sievers and Schmidtke; due to its simplicity and user friendliness (33). Valve morphology is classified according to the number of cusps and the presence of raphes, as well as the position and symmetry of the cusps. Type 0 has 2 symmetric leaflet/cusps and 1 commissure without evidence of a raphe, Type 1 has a single raphe due to fusion of the left coronary cusp with either the right or non-coronary cusp, and Type 2 arises when 2 raphes are present with fusion of both the right and non-coronary cusps (Figure 2). A functional (bicuspid) valve are classified as tricuspid valves with no raphe present, but there is fixation of the commissure between 2 cusps due to degenerative processes. Mylotte et al. used a modified Sievers classification system and observed higher rates of PVL in Sievers type 1 morphology (34.2\%) than in Sievers type 0 (13.3\%), possibly due to incomplete THV expansion due to calcified raphe and leaflet asymmetry (14).

Jilaihawi et al. proposed a classification system for BAV and described 3 subtypes, tricommissural, bicommisural raphe type, and bicommisural non-raphe type (11). The classification enabled a greater understanding of the interaction of the valve with the aortic-valvular complex at both the basal leaflet plane (presence or absence of a raphe) and at the commissural level (presence of 2 or 3 commissures). It was noted that the presence of a calcified raphe may impact on TAVI expansion and device apposition at the annulus. Tricommisural BAV type was not found to be associated with aortopathy and has widely been termed functional or acquired BAV disease. Tricommisural BAV arises from rheumatic, fibrotic, or calcific processes leading to focal commissural fusion (11). Tricommisural BAV disease is different from tricuspid valve aortic stenosis and may account for the higher incidence of PPM after TAVI. Interestingly, there were marked geographical differences between the subtypes of BAV. Non-raphe type bicommisural bicuspid AS was more 

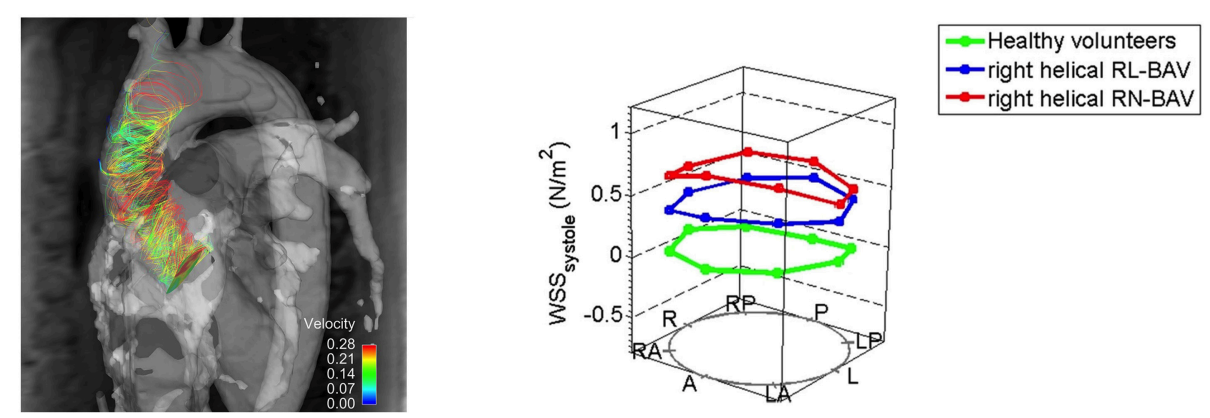

FIGURE 1 | Altered right-handed helical aortic flow patterns in patients with bicuspid aortic valve disease. Patients with right and non-coronary cusp fusion BAV had higher wall shear stress patterns in the ascending aorta [Reproduced with permission from the Bissell et al. (32)].
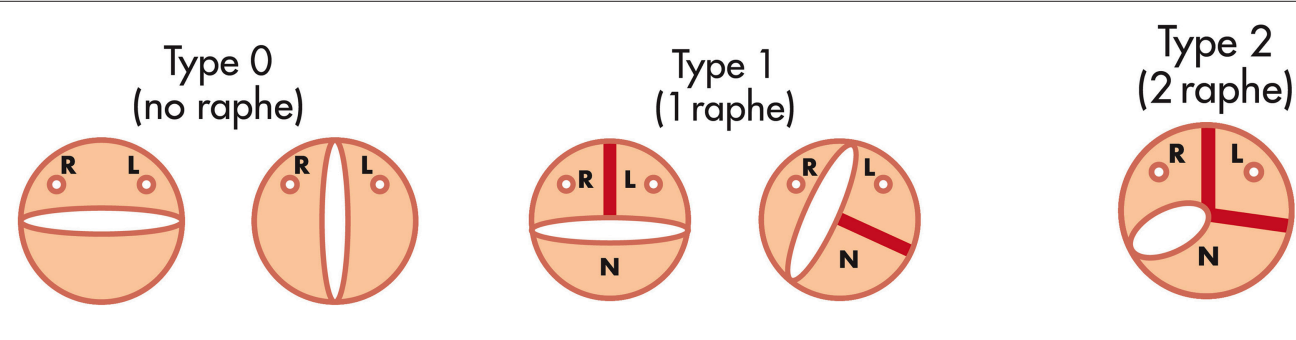

FIGURE 2 | The Sievers and Schmidtke classification system for bicuspid aortic valve [Adapted from Sievers et al. (33)].

common in Asia, but not in North America or Europe. The classification system did not predict the rates of moderate or severe PVL (tricommisural 19\%, bicommisural raphe type $19.5 \%$, and bicommisural non-raphe subtype 15\%). Thirty-day mortality rates according to the BAV subtypes were not found to be statistically different (tricommisural $4.2 \%$, bicommissural raphe subtype $2.7 \%$, and bicommisural non-raphe subtype $9.5 \%$ ). There was also no difference in new permanent pacemaker implantation rates between the BAV subtypes.

\section{CURRENT REGISTRY DATA ON BICUSPID AORTIC VALVE DISEASE}

Our current understanding of the safety and efficacy of treating BAV patients with TAVI is largely based on small registries, most of which used older generation THVs $(14,34,35)$. A multi-center study raised concerns regarding an excess of bioprosthetic PVL in bicuspid aortic valve disease patients undergoing TAVI (14). This was a retrospective registry of 139 patients across 12 centers collecting clinical, procedural, and follow-up data. Procedural mortality was $3.6 \%$, with THV embolization occurring in $2.2 \%$ with a 1 -year mortality of $17.5 \%$. MSCT-based TAVI sizing was used in $63.5 \%$ of patients. AR grade $2+$ post-TAVI was not infrequent at $28.4 \%$ which decreased to $17.4 \%$ when CT-sizing and planning algorithms were used. This series demonstrated that pre-procedural MSCT imaging can minimize PVL in TAVI for BAV disease by more accurately sizing the annulus. In a registry using a newer generation SAPIEN 3 valve, 51 patients with BAV disease from 8 centers were evaluated (13).
The incidence of trivial and no AR post-TAVI was $63 \%$ and mild AR was $37 \%$. The 30 -day mortality rate was reported at $3.9 \%$.

In a study of 130 patients with severe AS and BAV from 14 centers undergoing TAVI (11), the 30-day outcomes were comparable with those reported in patients with tricuspid valve stenosis $(1,2,7,36,37)$. There was however an excess of new pacemaker implantation which was similar for balloon expandable and self-expanding valves (Table 1). An increase in significant PVL was not observed in this study as compared with tricuspid valve stenosis patients undergoing TAVI. Once again, PVL rates were lower in this study if MSCT data was used for sizing.

The Bicuspid AS TAVI multicentre registry is the largest study to date evaluating 546 patients with either bicuspid or tricuspid AS who were propensity scored matched (12). Patients were recruited from Europe, North America and the Asia specific region. The patients with bicuspid severe AS had lower STS scores and represented an intermediate risk profile population, and furthermore the use of a large prostheses was more commonly associated with bicuspid AS patients. The major findings of this study were bicuspid severe AS patients had more frequent conversion to open surgery and a significantly lower device success rate as compared with propensity matched tricuspid AS patients. There were no significant betweengroup differences in procedural complications such aortic root injury and moderate-to-severe PVL when new generation devices were used. All-cause mortality at 2-year followup was comparable between the bicuspid and tricuspid groups. 
TABLE 1 | Summary of 30-day outcomes in the main TAVI trials in patients with bicuspid aortic stenosis.

\begin{tabular}{|c|c|c|c|c|c|c|c|c|c|c|c|c|}
\hline Study & $\begin{array}{c}\text { Patients } \\
\text { (n) }\end{array}$ & $\begin{array}{l}\text { BE } \\
(\%)\end{array}$ & $\begin{array}{l}\text { SE } \\
(\%)\end{array}$ & $\begin{array}{l}M E^{\star} \\
(\%)\end{array}$ & $\begin{array}{l}\text { Death } \\
(\%)\end{array}$ & $\begin{array}{c}\text { All } \\
\text { CVE } \\
(\%)\end{array}$ & $\begin{array}{c}\text { Valve } \\
\text { embolization } \\
(\%)\end{array}$ & $\begin{array}{c}\text { PVL > } \\
\text { Mild (\%) }\end{array}$ & $\begin{array}{c}\text { New PPM } \\
(\%)\end{array}$ & $\begin{array}{c}\text { Conversion } \\
\text { to surgery } \\
(\%)\end{array}$ & $\begin{array}{c}\text { Need for } \\
\text { second } \\
\text { valve (\%) }\end{array}$ & References \\
\hline Yoon et al. & 546 & 58 & 34 & 8 & 3.7 & 2.9 & NA & 10.4 & 15.4 & 2.0 & 4.8 & (12) \\
\hline Perlman et al. & 51 & 100 & 0 & 0 & 3.9 & 1.9 & 0 & 0 & 23.5 & 0 & 0 & (13) \\
\hline Jilaihawi et al. & 130 & 54 & 46 & 0 & 1.5 & 3.2 & 1.5 & 18.1 & 26.2 & 3.1 & 3.1 & (11) \\
\hline Mylotte et al. & 139 & 34 & 66 & 0 & 5.0 & 2.2 & 2.2 & 28.4 & 23.2 & 2.2 & 3.6 & (14) \\
\hline
\end{tabular}

$M E^{\star}$, mechanical expanding valve LOTUS valve; NA, not available; CVE, cerebrovascular event, stroke, or transient ischemic attack.

\section{PROSTHESIS CHOICE IN BICUSPID VALVE DISEASE}

Operators need to be cognisant of the potential advantages and disadvantages of balloon-expandable and self-expanding devices in the BAV space. Balloon-expandable valves exert greater radial force as compared with self-expanding devices and may circularize the native annulus minimizing potential sites for paravalvular leaks. Mylotte et al. (14) reported outcomes on both balloon-expandable and self-expanding devices observing a greater incidence of PVL $\geq 2$ with selfexpanding valves $(19.6 \%$ with Sapien XT and $32.2 \%$ with CoreValve). This may be attributable to the reduced radial strength in self-expanding devices increasing the likelihood of residual PVL. Conversely, when comparisons are made using newer generation balloon-expandable and self-expanding devices which feature an external sealing skirt there were no significant differences between the two general valve designs (38).

Rates of annular rupture have been reported to be as high as $5.3 \%$ in some series using the balloon-expandable Sapien XT valve (38). This may have been largely driven by a degree of oversizing required for device anchoring to prevent significant PVL. With improvements in design of the newer-generation balloon expandable valves there is sufficient anchoring with less oversizing which has led to acceptable rates of PVL and annular rupture $(39,40)$. When sizing is guided by CT annular measurements a degree of oversizing $(7-13 \%$ for the S3 THV design) appears to be safe with newer generation valves, leading to a reduction in AR in patients with bicuspid valve disease.

In a series of 51 patients who underwent TAVI in bicuspid AS using the new generation balloon expandable S3 valve, device success rate was reported to be $98 \%$ with no cases of moderate to severe aortic regurgitation (13). Improvements in design of the newer generation S3 THVs have resulted in a lower profile device with more accurate positioning, and improved sealing with its polyethylene terephthalate outer skirt. The Lotus mechanical expanding valve has an outer adaptive seal with the ability to be repositioned and retrieved. Promising results were also demonstrated with regards device success when this device was used to treat bicuspid AS patients (38).

\section{NEW PERMANENT PACEMAKER IMPLANTATION RATES FOR TAVI IN BICUSPID VALVE DISEASE}

One of the main limitations of TAVI in tricuspid valve severe AS compared with SAVR is the high incidence of conduction abnormalities. New permanent pacemaker implantation has emerged to be an important short-term complication; reported to be around $6.0 \%$ for balloon expandable valves and up to $28.0 \%$ for self-expanding valves $(41,42)$. There are no specific design advances that have been incorporated in the newer generation THVs to reduce the risk of permanent pacemaker implantation. Moreover, there has been a reported increase in conduction abnormalities with newer generation devices (43). Mauri et al. identified technical and anatomical factors predisposing to new permanent pacemaker implantation (44). In this study using the new generation SAPIEN 3 THV, 33 of 229 patients received a pacemaker following TAVI. Pre-existing RBBB, left ventricular outflow tract calcification and an implantation depth defined as $>25.5 \%$ of the stent frame below the annulus were each found to be important predictors of new permanent pacemaker implantation. This study highlighted important technical factors such as reducing the depth of the valve implant by a mere $3 \mathrm{~mm}$ reduced the need for permanent pacemaker implantation by $52 \%$. TAVI operators will need to consider such technical aspects to reduce pacing rates, yet balance these with the risk of THV embolization with higher implants (45).

For bicuspid valve severe AS, pacemaker implantation rates were similar for balloon expandable (BE) and self-expanding (SE) THVs $(11,14)$. Jilaihawi et al. reported pacing rates of $25.5 \%$ for balloon expanding valves and $26.9 \%$ for self-expanding valves (11). Mylotte et al. also reported higher than expected pacing rates (16.7\% for balloon expanding and $26.7 \%$ for self-expanding valves) in TAVI patients (14).

It has been postulated that the higher incidence of PPM implantation rates in BAV patients is related to asymmetric THV expansion due to resistant calcified raphe and leaflet fusion. There may be preferential expansion posteriorly to the noncoronary cusp which lies adjacent to the atrioventricular node. In tricuspid valve disease or incomplete raphe type BAV, there may be a more symmetrical expansion of THVs, thus diverting tissue away from the AV node (11). The presence of bulky calcification in the Sievers L-R Type 1 BAV may cause protrusion 
toward the membranous part of the interventricular septum leading to atrioventricular and intraventricular conduction block (46). The higher pacemaker rates may thus be associated with difficulty in valve positioning due to irregular leaflet shape and inability to achieve a coaxial position during valve deployment. This can often lead to lower implantation depths, known to be associated with higher pacing rates. Patients with BAV disease also tend to be younger, and as TAVI moves to intermediate and the low-risk, complications such as pacemaker implantations will be important. Understanding the factors contributing to new permanent pacemaker implantation need to be addressed with particular focus on implantation depth and important calcification in the left ventricular outflow tract.

\section{CORONARY OCCLUSION AND ANNULAR RUPTURE}

The data on acute coronary occlusion during TAVI stems from isolated case reports and case series. The incidence is reported to be $<1 \%$ and is a rare yet potentially life-threatening $(4,47-$ 52). Randomized control trials of patients with tricuspid severe AS; report an acute coronary obstruction incidence of $0.1-1.2 \%$. Data from bicuspid TAVI registry data report a similar $0-1.5 \%$ incidence of acute coronary obstruction (11-14, 38). Certain factors may increase the risk of coronary obstruction post-TAVI such as female sex, coronary ostia height of $<10 \mathrm{~mm}$, sinus of Valsalva dimensions and the presence of severe valve calcification (53). Most reported cases of coronary obstruction post-TAVI received a balloon-expandable $\mathrm{THV}$.

Recent reports have arisen of the development of delayed coronary obstruction (DCO) occurring hours or days following TAVI. In a recently published international registry of 17,092 patients undergoing TAVI, the reported incidence of delayed coronary obstruction was $0.22 \%$ (54). DCO can be divided into early (0-7 days) and late ( $>7$ days) post-TAVI. The etiology of DCO relates to a number factors such as a narrow sinuses of Valsalva, low coronary heights, excessive calcification, valvein-valve TAVI and pharmacological factors such as antiplatelet and anticoagulation (54). Aortic root injury and annulus rupture likewise is a rare complication in BAV undergoing TAVI; reported to have an incidence ranging from 0 to $2 \%$ in the reported literature $(11-14,38)$.

\section{COMPARISON OF OUTCOMES BETWEEN OLD AND NEWER GENERATION THVS IN BAV}

THV device iteration significantly addressed the shortcomings of earlier generation THVs which were limited by PVL. Significant PVL post-TAVI has been shown to correlate with increased mortality (37, 55-57). PVL rates have improved significantly with newer-generation devices for patients with tricuspid AS patients, and has also been seen when newer-generation THVs are used in BAV patients (13). In a recently reported BAV registry comparing older versus newer generation THVs in BAV, moderate or severe paravalvular leak was significantly less frequent with newgeneration devices compared to early generation devices ( 0.0 vs. $8.5 \% ; p=0.002)$, which resulted in a higher device success rate (92.2 vs. $80.9 \% ; p=0.01$ ) (38). When compared with TAVI in tricuspid valve stenosis, there were no differences in procedural related complications with new generation devices. This was true for cumulative mortality at 2 years which were similar for tricuspid and bicuspid valves with newer generation devices (12). This has also been seen in several other registries using the SAPIEN 3 valve in tricuspid AS (58-61). Improvements in PVL have largely been made by developing a poly-ethylene terephthalate sealing skirt along with more accurate positioning. With the Lotus valve, the incidence of moderate to severe PVL has been reported to be as low as $2.0 \%$, largely due to the adaptive seal and optimal positioning due to device retrievability and repositionability (62).

\section{TECHNICAL CONSIDERATIONS FOR TAVI IN BAV}

BAV disease poses many technical challenges for TAVI operators. Selection of the optimal angiographic projection and visualization of the aortic annulus can be difficult due to the asymmetric shape of the cusps and sinus of Valsalva. Calcium distribution throughout the aorto-annular complex is frequently asymmetric, along with raphe resistant to pre-dilatation and aortic root dilatation. These variations may promote poor valve expansion and thus adversely affect valve hemodynamics and durability which in turn can lead to high transvalvular gradients, PVL, device malpositioning, and higher permanent pacemaker rates post-TAVI $(11,12,14,63)$. The aortic annulus is often elliptical in shape, larger in size, and associated with a dilated and horizontal aorta, (64) further giving rise to difficulties in device positioning and expansion. The native valve leaflets can be capacious due to leaflet fusion resulting in longer leaflets increasing the risk of coronary obstruction $(34,65)$.

Himbert et al. reported on the use of self-expanding devices in 15 patients with BAV disease (66). The device was associated with non-circular expansion at the annular level which was less frequent when the device was implanted lower in the left ventricular outflow tract. In another series of 21 patients who had post-procedural MSCT imaging, non-circular expansion of the valve was seen more commonly with self-expanding valves due to the asymmetrical nature of the bicuspid valve orifice and resistant raphe (67). With balloon-expandable valves there have been reports of asymmetric longitudinal valve expansion, however further assessment is required for both self-expanding and balloon-expandable valves to ascertain if this ultimately affects leaflet motion and durability (13).

\section{Imaging for TAVI in Bicuspid-Aortic Valve Disease}

Sizing of THVs can be difficult due to multiple anatomical considerations including a large and eccentric annulus, calcified raphe, horizontal aorta, complex calcification, and aortic root 
dilatation. Each of these variables can interplay and make TAVI implantation technically challenging. MSCT has enabled operators to have a better understanding of the anatomy of BAV disease, critical for procedural planning pre-TAVI to minimize complications (68).

Due to the percutaneous nature of TAVI, operators lack the ability to expose the surgical field and directly visualize the aortic valve, annulus and structures around it. MSCT is used to provide a comprehensive 3-dimensional data-set of the aortic valve anatomy and identification of concomitant aortopathy. MSCT provides anatomical measurements of the aortic annulus, detail of the aortic valve, calcium burden, aortic root ("sinus of Valsalva"), coronary ostia and access site, all of which are essential to minimize complications and improve procedural outcomes. In BAV, MSCT is key to providing information on leaflet morphology, symmetry of the valve leaflets, presence of raphe and the location of calcification all of which can influence the type and size of THV selected (Figure 3) (69).

In a study using MSCT which looked at the shape and size of the annulus in bicuspid $(n=200)$ and tricuspid valves $(n=200)$, the aortic annulus was found to be less elliptical in bicuspid than tricuspid valves (ellipticity index 1.24 vs. 1.29, respectively). This study also highlighted that biscuspid valve patients had large annular areas compared with tricuspid valves (5.21 vs. 4.63 $\mathrm{cm}^{2}$ ) (27). Reports from recent large series of bicuspid patients indicate that annular dimensions still fall within the valve sizing recommendations for current commercially available THVs (13, 14, 67).

THV oversizing can lead to distortion and poor expansion of the valve prosthesis leading to PVL. This can be improved with intra-procedural post-dilatation, however there is a risk of annular rupture, aortic root haematoma and heart block with subsequent post-dilatations. A self-expanding THV may minimize the risk of annular rupture, however when compared with balloon expandable THVs, there is a greater incidence of PVL and heart block in BAV disease patients $(38,70)$.

\section{Balloon Sizing}

Other techniques can be used to help with valve sizing such as fluoroscopic balloon sizing of the aortic valve annulus pre-TAVI (71). Balloon sizing can complement MSCT especially when there is ambiguity regarding valve sizing and when measurements fall in the "gray zone" between two valve sizes. In the presence of bulky cusps or long leaflets, balloon sizing can mimic valve implantation and also identify patients at risk of coronary obstruction. It provides additional information that is not available from MSCT or transoesphageal echocardiography (TEE) and can help predict how situations such as severe, eccentric calcification may behave and the complications that can arise from it.

Commonly in BAV disease the abnormal geometry at the annular level and unequal-sized leaflets makes alignment of the two or three hinge points (depending on BAV type) difficult. MSCT is useful in tricuspid valve disease to find the optimal implantation projection of the aortic root and an orthogonal alignment of the native annulus. This however, is often found to be unhelpful in BAV disease. Techniques have been described using the pigtail catheter and altering the fluoroscopic projection to find an optimal view for implantation; "follow the right cusp rule" (72) and the "Right cusp rule, Part II" (73).

\section{Valve Crossing}

Crossing the stenotic BAV may be challenging and time-consuming, increasing the risk of embolic cerebral complications. Careful interrogation of the MSCT can identify the fused cusps in BAV disease and may help with predicting the location of valve opening and maximize the chance of the wire to cross. Frangieh et al. (68) have described a step by step approach to crossing a stenotic BAV. Wire movement should start from the non-fused leaflet ("single cusp") which has no raphe and then with careful rotation direct the wire in small steps toward the fused cusps. If starting in the NCC rotate clockwise, or anticlockwise if starting in the LCC. In BAV with no raphe, there are only two anatomical cusps and the guide wire should be slowly manipulated between each cusp carefully interrogating the opening between the leaflets. In more angulated aortic roots, catheters with a bigger curve such as an Amplatz-2 (AL-2) may help with retrograde crossing, and/or softer hydrophilic coated wires such as the Glidewire. In extreme circumstances when conventional retrograde wire crossing of the BAV is not possible, ad hoc trans-septal puncture followed
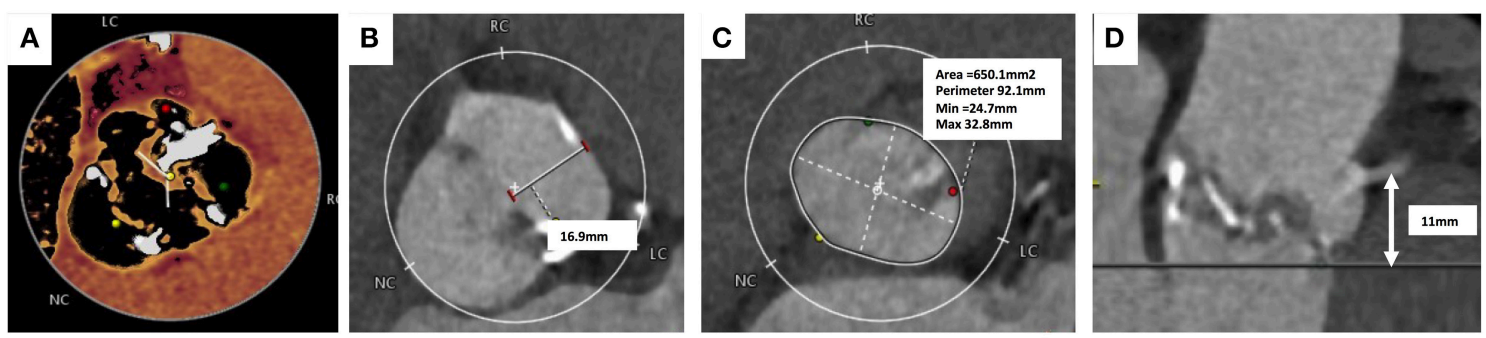

FIGURE 3 | Computer Tomography Imaging of bicuspid aortic valve. (A) Sievers Type 1 Raphe-type bicuspid aortic valve (BAV) with mixed cusp fusion (left-right). (B) Large bulky cusps measuring $16.9 \mathrm{~mm}$ maximum diameter. (C) Asymmetric large annulus. (D) Low lying coronary ostia at $11 \mathrm{~mm}$ combined with large bulky leaflets indicate a risk of coronary occlusion during TAVI. 
by wire delivery into the left ventricular apex, anterograde aortic valve crossing, wire externalization and subsequent aorto-venous loop creation can be undertaken. A catheter of choice (i.e., $\mathrm{AL}$ ) can then be placed retrogradely across the stenotic BAV thus facilitating regular fully percutaneous transfemoral TAVI (Figure 4) $(74,75)$.

\section{HOW TO PERFORM TAVI IN BICUSPID AORTIC VALVE DISEASE}

Historically, patients with BAV disease with severe AS were referred for SAVR. However, there is an increasing tendency for some younger patients to opt for a less invasive percutaneous

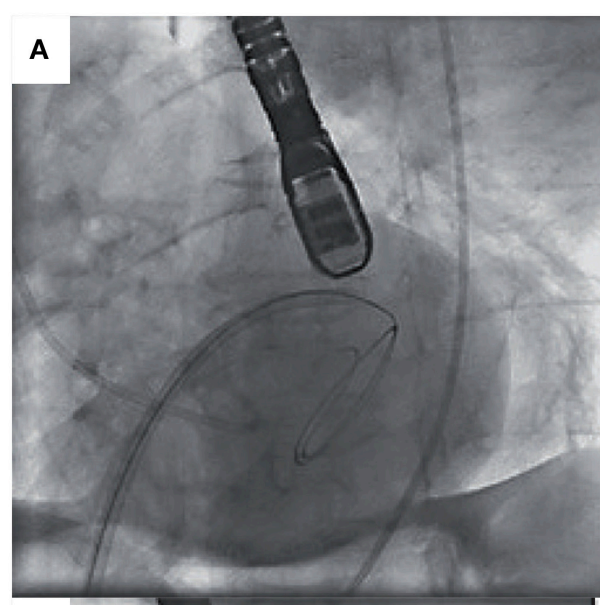

B

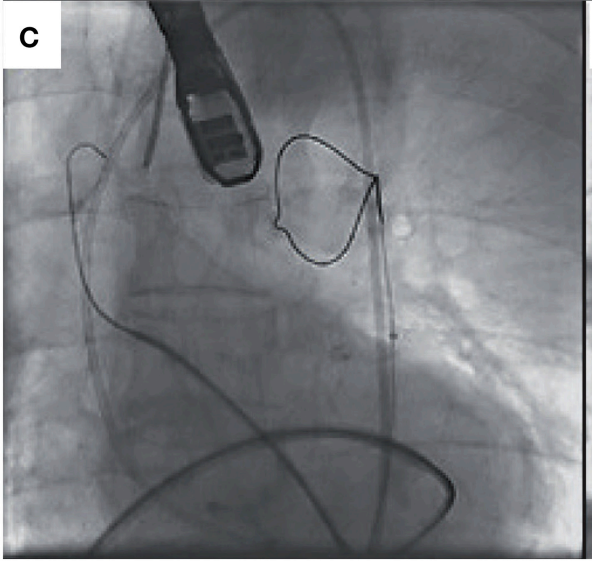

D

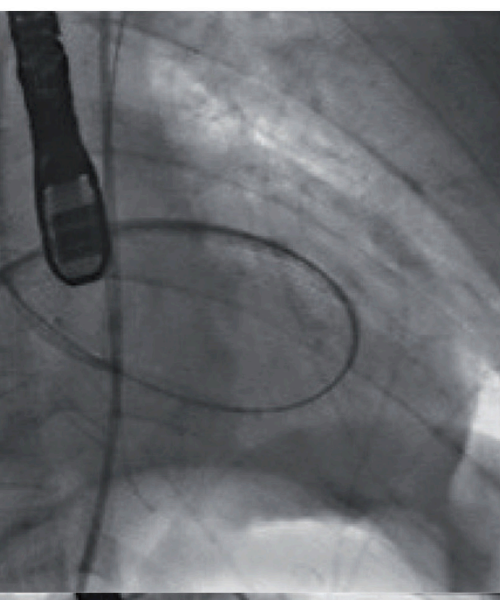

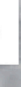

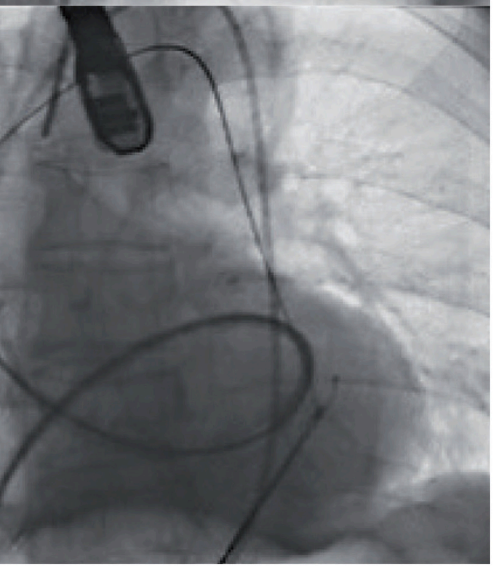

FIGURE 4 | (A) Transeptal puncture and positioning of hydrophilic wire and Judkins Right in the left ventricle. (B) Anterograde crossing of the aortic valve and wire changed for exchange wire. (C) Amplatz Goose Neck Snare used to snare the exchange wire. (D) Exchange wire then externalized via the left femoral artery [Adapted with permission from the Rodríguez-Olivares et al. (75)].
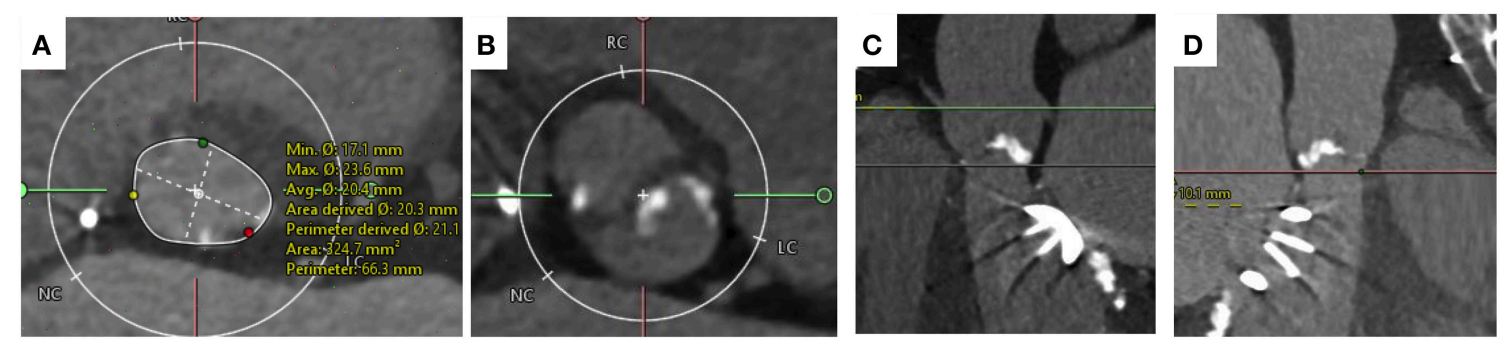

FIGURE 5 | MSCT imaging of bicuspid aortic valve. (A) Annulus measurement with minimum diameter of $17 \mathrm{~mm}$ and maximum diameter of $24 \mathrm{~mm}$ and area of 325 $\mathrm{mm}^{2}$. (B) Cross-sectional view taken $4 \mathrm{~mm}$ above the level of the annulus. The valve is a Type 0 Sievers BAV with no raphe. (C) Distance to coronary ostia $>10 \mathrm{~mm}$. (D) The distance from the aortic annulus to the mitral valve ring measures $10.1 \mathrm{~mm}$ acceptable for TAVI implantation. 
procedure, particularly in the presence of significant comorbidity or prior cardiac surgery. The selection of the type and size of the valve can be challenging due to the anatomical reasons outlined above, with MSCT playing an important role in THV device selection and implantation technique. Sizing and implantation technique is key to success in TAVI in bicuspid valve disease. Due the asymmetric nature of the aortic annulus, eccentric heavy calcification and raphe resistant to dilation, THV valves are implanted higher and anchored at the tightest part of the commissural. This has in part led to sizing of valves at $+4 \mathrm{~mm}$ above the annulus at the intercommisural space. The final implantation depth are often higher due to the anchoring effect of the calcification at the level of the commisures with $<4 \mathrm{~m}$ for CoreValve, $<3 \mathrm{~mm}$ for CoreValve Evolute $\mathrm{R}$ (Medtronic, Minneapolis, Minnesota) and atrio-ventricular ratio of 60/40 for Sapien XT/S3 (Edwards Lifesciences, Minnesota). Here we present 2 illustrative cases of how to perform TAVI in BAV.

\section{Case 1}

A 67-year old female with acute respiratory failure due to severe AS was referred for consideration of TAVI. She underwent ventricular septal defect repair at the age of 10. At the age of 57 she presented with progressive breathlessness secondary to severe mitral regurgitation and underwent a mitral valve replacement with a $27 \mathrm{~mm}$ Carpentier Edwards Magna Valve. Six years later she developed further progressive dyspnoea and underwent an urgent redo mitral valve replacement for a stenotic prosthetic mitral valve. A $33 \mathrm{~mm}$ Carbomedics Valve was inserted into the mitral position. She has end-stage renal disease requiring haemodialysis.

Transthoracic echocardiography showed a degenerated bicuspid aortic valve with a peak velocity of $5.2 \mathrm{~m} / \mathrm{s}$ (peak gradient $108 \mathrm{mmHg}$; mean gradient $68 \mathrm{mmHg}$, area of 0.43 $\mathrm{cm}^{2}$ ). The mitral valve prosthesis was functioning normally. Invasive coronary angiography revealed normal coronary arteries. Following a Heart team discussion, it was decided to perform TAVI due to her previous mitral and redo mitral valve replacement. The aortic valve was a Sievers Type 0 bicuspid valve. The aortic annulus minimum diameter was $17 \mathrm{~mm}$, maximum diameter $24 \mathrm{~mm}$, perimeter $69 \mathrm{~mm}$, and an area of $355 \mathrm{~mm}^{2}$ (Figure 5). The common femoral arteries measured $6 \mathrm{~mm}$ bilaterally. A technical concern regarding TAVI in this lady was the interaction of the TAVI valve with the mitral valve prosthesis and the risk of valve embolization
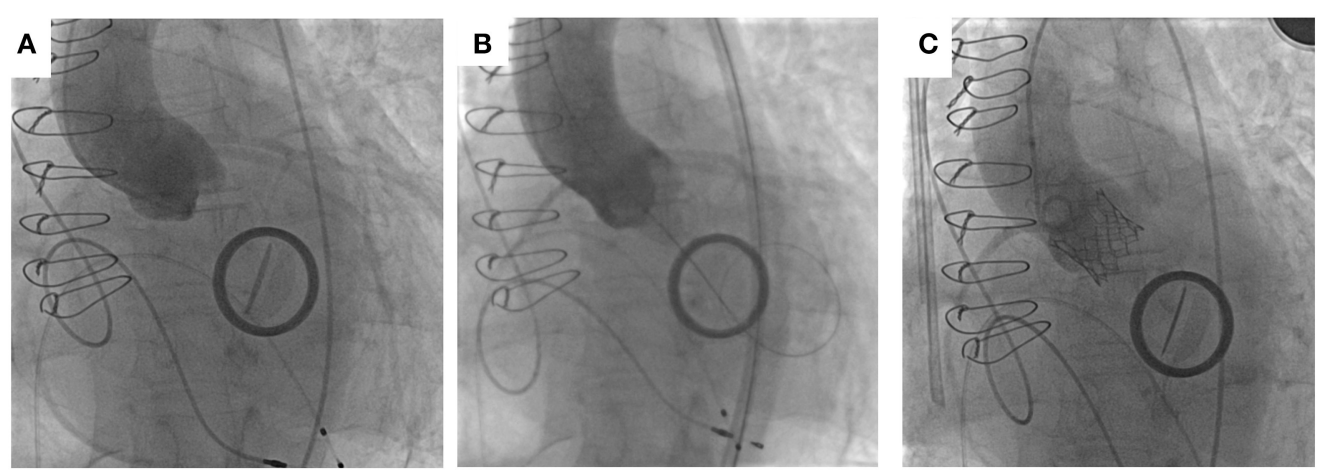

FIGURE 6 | Implantation of SAPIEN 3 in patient with bicuspid aortic valve with previous mitral valve replacement. (A) Aortogram for root alignment with pigtail catheter in the right coronary cusp. (B) Balloon sizing with $20 \mathrm{~mm}$ balloon touching hinge points with simultaneous aortogram showing filling of coronary arteries.

(C) Successful deployment of $23 \mathrm{~mm}$ SAPIEN 3 valve with no paravalvular leakage.
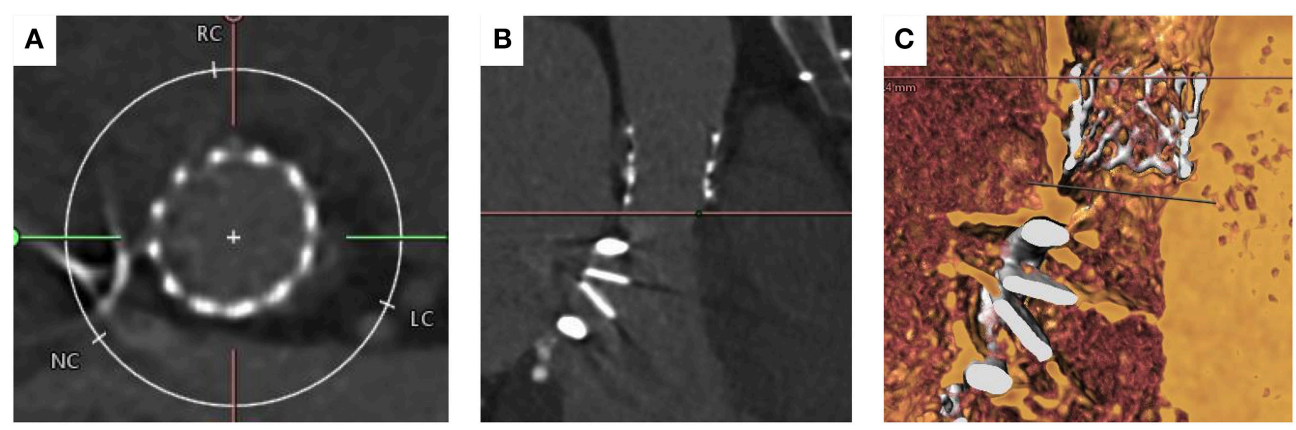

FIGURE 7 | MSCT imaging of the aortic annulus post TAVI implantation with $23 \mathrm{~mm}$ Edwards Sapien Valve. (A) shows circular deployment of the transcatheter heart valve. (B) Left ventricular outflow tract view showing bi-leaflet mitral valve prosthesis and TAVI valve post deployment. (C) Volume rendered imaging confirming there is no interaction between the base of the TAVI valve and mitral valve prosthesis. 
during deployment. The MSCT identified the rim between the mitral valve prosthesis and the aortic annulus to measure $10 \mathrm{~mm}$, which was felt to provide an adequate landing zone for the THV, with the risk of valve embolization deemed to be small.

The right femoral artery was cannulated and a 14 French Esheath was introduced. The annulus area was felt to be between two valve sizes (23and $26 \mathrm{~mm}$ Sapien S3 valves). The valve was crossed retrogradely using an Amplatz Left1 diagnostic catheter and a "straight" standard wire. The wire was then exchanged with a pre-shaped small Safari wire (Boston Scientific, Natick, MA, USA). A balloon aortic valvuloplasty was performed and simultaneous aortogram was performed. An aortogram confirmed that during inflation the $20 \mathrm{~mm}$ balloon adequately filled the aortic annulus and was in contact with the hinge points (Figure 6). Coronary filling was also visualized. It was therefore decided to implant a $23 \mathrm{~mm}$ Edwards Sapien S3 Valve. Careful attention was given during valve positioning ensuring the valve skirt was positioned just below the hinge points. The valve was confirmed to be well positioned with good hemodynamics without paravalvular regurgitation. Following valve deployment, MSCT was performed confirming circular expansion of the valve and no infringement on the mitral valve prosthesis (Figure 7).

In cases of BAV, large aortic annuli pose a challenge for the TAVI operator as large annular dimensions fall outside the recommended sizing ranges for currently available THVs. There are concerns regarding significant paravalvular leakage post TAVI deployment in this group of patients. In certain cases with large annuli the inter-commisural space can be used for the landing zone with good effect. Improvements in THV design (in particular the sealing skirt) and technical considerations such as landing the valve in the inter-commisural space means that these patients can be treated with good outcomes. This forms the rationale of some TAVI operators who suggest to size and land the THV $4 \mathrm{~mm}$ above the measured annulus.

\section{Case 2}

A 58 year-old male with end stage renal disease due to IgA nephropathy who had previously undergone a renal transplant which had failed was declined for redo renal transplantation. He had progressive dyspnoea and a history of syncope on exertion.
The transthoracic echocardiogram confirmed severe stenosis of a BAV with a peak velocity of $3.9 \mathrm{~m} / \mathrm{s}$ (peak gradient $61 \mathrm{mmHg}$, mean gradient of $39 \mathrm{mmHg}$ and area of $0.89 \mathrm{~cm}^{2}$ ). There was also the presence of moderate aortic regurgitation. Coronary angiography revealed non-flow limiting coronary artery disease. MSCT confirmed a Sievers Type 1 bicuspid valve with a partial raphe between the right and left cusps. The aortic annulus was large with a perimeter measuring $98 \mathrm{~mm}$, mean Sinus of Valsalva diameter of $40 \mathrm{~mm}$ and an inter-commisural distance of $29 \mathrm{~mm}$ (Figure 8). Both common femoral arteries were of large caliber and measured $8 \mathrm{~mm}$ on the left and $9 \mathrm{~mm}$ on the right. Following discussion by the Heart team and careful analysis of the MSCT it was felt that TAVI was technically possible if deployed at the inter-commisural space.

TAVI was performed under local anesthetic and the right femoral artery was cannulated and a $20 \mathrm{Fr}$ sheath was inserted. The left femoral artery was cannulated and a 7 Fr sheath was inserted. The left femoral vein was used for insertion of a temporary pacemaker lead. The bicuspid aortic valve was crossed retrogradely using a Amplatz Left 1 diagnostic catheter and a hydrophilic coated straight tipped Glidewire. This was exchanged for a pre-shaped Safari wire and placed in the left ventricular apex. A balloon valvuloplasty was performed using a $25 \mathrm{~mm}$ balloon and a simultaneous aortogram was performed. The aortogram revealed a leak of contrast into the left ventricular cavity during balloon aortic valvuloplasty and felt to be an inadequate seal. A $34 \mathrm{~mm}$ Evolut CoreValve was deployed at the level of the leaflet tips, with hemodynamics and echocardiography confirming a good result with no significant PVL. The peak velocity across the TAVI valve was $1.8 \mathrm{~m} / \mathrm{s}$, peak gradient of $14 \mathrm{mmHg}$ and area of 1.11 $\mathrm{cm}^{2}$.

\section{CONCLUSIONS}

Despite encouraging data, especially with newer generation THVs for BAV disease, caution needs to be taken as patients with bicuspid AS are more likely to be younger (12, 38, 76) and therefore concerns regarding significant PVL and high permanent pacemaker implantation rates need to be
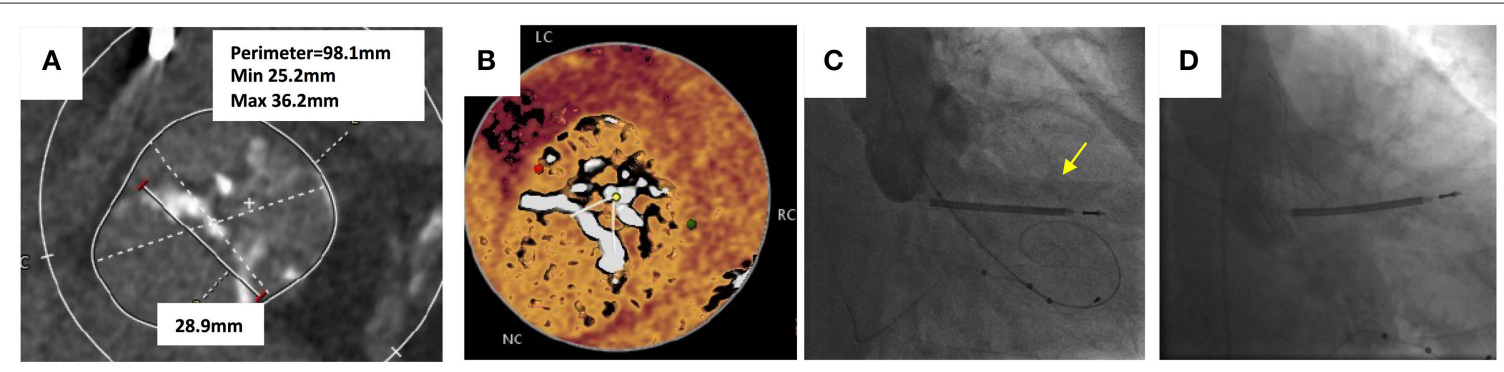

FIGURE 8 | Transcatheter aortic valve replacement in bicuspid aortic valve. (A) Sievers Type 1 bicuspid valve with partial raphe between the right and left cusps. Large annulus with perimeter measuring $98.1 \mathrm{~mm}$ and an intercommisural distance of $28.9 \mathrm{~mm}$. (B) "Hockey puck" view of the bicuspid valve shows partial raphe between left and cusps. (C) Balloon valvuloplasty with $25 \mathrm{~mm}$ balloon for sizing prior to TAVI implantation. Yellow arrow shows leak of contrast into left ventricle during simultaneous aortogram indicating inadequate seal. (D) $34 \mathrm{~mm}$ Evolute R deployed at leaflet tips with no paravalvular leak. 
addressed before offering it to younger and lower operative risk patients. With improvements in the design of the sealing skirts of THVs, PVL rates have reduced and the ability to reposition and retrieve the devices have led to more technical success with TAVI in selected patients with BAV disease. Procedural success is high and the survival rates are similar to those in patients with tricuspid valve AS undergoing TAVI. However, complications such as moderate or severe PVL and aortic root dissection are more common in BAV disease compared to tricuspid aortic valve patients. As the indications for TAVI expands with data supporting its use in the younger and intermediate risk group patients, the proportion of patients with BAV is expected rise. Specifically designed prospective studies are required to provide further evidence on durability, anatomical selection criteria and long-term

\section{REFERENCES}

1. Popma JJ, Adams DH, Reardon MJ, Yakubov SJ, Kleiman NS, Heimansohn $\mathrm{D}$, et al. Transcatheter aortic valve replacement using a self-expanding bioprosthesis in patients with severe aortic stenosis at extreme risk for surgery. J Am Coll Cardiol. (2014) 63:1972-81. doi: 10.1016/j.jacc.2014.02.556

2. Adams DH, Popma JJ, Reardon MJ, Yakubov SJ, Coselli JS, Deeb GM, et al. Transcatheter aortic-valve replacement with a self-expanding prosthesis. $N$ Engl J Med. (2014) 370:1790-8. doi: 10.1056/NEJMoa1400590

3. Leon MB, Smith CR, Mack M, Miller DC, Moses JW, Svensson LG, et al. Transcatheter aortic-valve implantation for aortic stenosis in patients who cannot undergo surgery. N Engl J Med. (2010) 363:1597-607. doi: 10.1056/NEJMoa1008232

4. Smith CR, Leon MB, Mack MJ, Miller DC, Moses JW, Svensson LG, et al. Transcatheter versus surgical aortic-valve replacement in high-risk patients. N Engl J Med. (2011) 364:2187-98. doi: 10.1056/NEJMoa1103510

5. Leon MB, Smith CR, Mack MJ, Makkar RR, Svensson LG, Kodali SK, et al. Transcatheter or surgical aortic-valve replacement in intermediate-risk patients. N Engl J Med. (2016) 2016:1609-20. doi: 10.1056/NEJMoa1514616

6. Reardon MJ, Van Mieghem NM, Popma JJ, Kleiman NS, Søndergaard L, Mumtaz M, et al. Surgical or transcatheter aortic-valve replacement in intermediate-risk patients. $N$ Engl J Med. (2017) 376:1321-31. doi: 10.1056/NEJMoa1700456

7. Thyregod HG, Steinbruchel DA, Ihlemann N, Nissen H, Kjeldsen BJ, Petursson $\mathrm{P}$, et al. Transcatheter versus surgical aortic valve replacement in patients with severe aortic valve stenosis: 1-year results from the all-comers NOTION randomized clinical trial. J Am Coll Cardiol. (2015) 65:2184-94. doi: 10.1016/j.jacc.2015.03.014

8. Thourani VH, Kodali S, Makkar RR, Herrmann HC, Williams M, Babaliaros $\mathrm{V}$, et al. Transcatheter aortic valve replacement versus surgical valve replacement in intermediate-risk patients: a propensity score analysis. Lancet (2016) 387:2218-25. doi: 10.1016/S0140-6736(16)30073-3

9. Kapadia SR, Leon MB, Makkar RR, Tuzcu EM, Svensson LG, Kodali S, et al. 5-year outcomes of transcatheter aortic valve replacement compared with standard treatment for patients with inoperable aortic stenosis (PARTNER 1): a randomised controlled trial. Lancet (2015) 385:2485-91. doi: 10.1016/S0140-6736(15)60290-2

10. Mack MJ, Leon MB, Smith CR, Miller DC, Moses JW, Tuzcu EM, et al. 5-year outcomes of transcatheter aortic valve replacement or surgical aortic valve replacement for high surgical risk patients with aortic stenosis (PARTNER 1): a randomised controlled trial. Lancet (2015) 385:2477-84. doi: 10.1016/S0140-6736(15)60308-7

11. Jilaihawi H, Chen M, Webb J, Himbert D, Ruiz CE, Rodés-Cabau J, et al. A bicuspid aortic valve imaging classification for the TAVR era. JACC Cardiovasc. Imaging (2016) 9:1145-58. doi: 10.1016/j.jcmg.2015.12.022

12. Yoon SH, Bleiziffer S, De Backer O, Delgado V, Arai T, Ziegelmueller $\mathrm{J}$, et al. Outcomes in transcatheter aortic valve replacement for bicuspid success before it becomes a viable option for patients with BAV.

\section{AUTHOR CONTRIBUTIONS}

$\mathrm{RD}$ and $\mathrm{RP}$ wrote the manuscript and provided substantial contribution to the discussion and content. All the authors researched data for the article, and reviewed and/or edited the manuscript before submission.

\section{ACKNOWLEDGMENTS}

The authors can confirm that full written informed consent was obtained from the patients for publication of the case reports included in this review. versus tricuspid aortic valve stenosis. J Am Coll Cardiol. (2017) 69:2579-89. doi: 10.1016/j.jacc.2017.03.017

13. Perlman GY, Blanke P, Dvir D, Pache G, Modine T, Barbanti M, et al. Bicuspid aortic valve stenosis: favorable early outcomes with a next-generation transcatheter heart valve in a multicenter study. JACC Cardiovasc Interv. (2016) 9:817-24. doi: 10.1016/j.jcin.2016.01.002

14. Mylotte D, Lefevre T, Søndergaard L, Watanabe Y, Modine T, Dvir D, et al. Transcatheter aortic valve replacement in bicuspid aortic valve disease. J Am Coll Cardiol. (2014) 64:2330-9. doi: 10.1016/j.jacc.2014.09.039

15. Michelena H, Prakash S, Della Corte A, Bissell M, Anavekar N, Mathieu P, et al. Bicuspid aortic valve: identifying knowledge gaps and rising to the challenge from the International Bicuspid Aortic Valve Consortium (BAVCon). Circulation (2014) 129:2691-704. doi: 10.1161/CIRCULATIONAHA.113.007851

16. Hahn RT, Roman MJ, Mogtadek AH, Devereux RB. Association of aortic dilation with regurgitant, stenotic and functionally normal bicuspid aortic valves. J Am Coll Cardiol. (1992) 19:283-88. doi: 10.1016/0735-1097(92)90479-7

17. Olson LJ, Subramanian R, Edwards WD. Surgical pathology of pure aortic insufficiency: a study of 225 gases. Mayo Clin Proc. (1984) 59:835-41. doi: 10.1016/S0025-6196(12)65618-3

18. Nkomo VT, Enriquez-Sarano M, Ammash NM, Melton LJ, Bailey $\mathrm{KR}$, Desjardins V, et al. Bicuspid aortic valve associated with aortic dilatation. Arterioscler Thromb Vasc Biol. (2003) 23:351-6. doi: 10.1161/01.ATV.0000055441.28842.0A

19. Keane MG, Wiegers SE, Plappert T, Pochettino A, Bavaria JE, Sutton MG. Bicuspid aortic valves are associated with aortic dilatation out of proportion to coexistent valvular lesions. Circulation (2000) 102(19 Suppl 3):III35-9. doi: 10.1161/01.CIR.102.suppl_3.III-35

20. Pachulski RT, Weinberg AL, Chan KL. Aortic aneurysm in patients with functionally normal or minimally stenotic bicuspid aortic valve. Am J Cardiol. (1991) 67:781-2. doi: 10.1016/0002-9149(91)90544-U

21. Michelena HI, Desjardins VA, Avierinos, J.-F., Russo A, Nkomo VT, Sundt TM, et al. Natural history of asymptomatic patients with normally functioning or minimally dysfunctional bicuspid aortic valve in the community. Circulation (2008) 117:2776-84. doi: 10.1161/CIRCULATIONAHA.107.740878

22. Kong WK, Regeer MV, Ng AC, McCormack L, Poh KK, Yeo TC, et al. Sex differences in phenotypes of bicuspid aortic valve and aortopathy. Circ Cardiovasc Imaging (2017) 10:e005155. doi: 10.1161/CIRCIMAGING.116.005155

23. Roberts WC, Ko JM, Garner WL, Filardo G, Henry AC, Hebeler RF, et al. Valve structure and survival in octogenarians having aortic valve replacement for aortic stenosis ( \pm aortic regurgitation) with versus without coronary artery bypass grafting at a single US medical center (1993 to 2005). Am J Cardiol. (2007) 100:489-95. doi: 10.1016/j.amjcard.2007.0 3.050 
24. Jilaihawi H, Wu Y, Yang Y, Xu L, Chen M, Wang J, et al. Morphological characteristics of severe aortic stenosis in China: imaging corelab observations from the first Chinese transcatheter aortic valve trial. Catheter Cardiovasc Interv (2015) 85:752-61. doi: 10.1002/ccd.25863

25. Ward C. Clinical significance of the bicuspid aortic valve. Heart (2000) 83:81-5. doi: 10.1136/heart.83.1.81

26. Ng AC, Wang WY, Delgado V, Bax JJ. Bicuspid aortic valve disease: new insights. Struct Heart (2017). doi: 10.1080/24748706.2017.1329572

27. Bissell MM, Biasiolli L, Oswal A, Loudon M, Hess AT, Watkins H, et al. Inherited aortopathy assessment in relatives of patients with a bicuspid aortic valve. J Am Coll Cardiol. (2017) 69:904-6. doi: 10.1016/j.jacc.2016.11.068

28. Bissell MM, Hess AT, Biasiolli L, Glaze SJ, Loudon M, Pitcher A, et al. Aortic dilation in bicuspid aortic valve disease: flow pattern is a major contributor and differs with valve fusion type. Circ Cardiovasc Imaging (2013) 6:499-507. doi: 10.1161/CIRCIMAGING.113.000528

29. Mahadevia R, Barker AJ, Schnell S, Entezari P, Kansal P, Fedak PW, et al. Bicuspid aortic cusp fusion morphology alters aortic three-dimensional outflow patterns, wall shear stress, and expression of aortopathy. Circulation (2014) 129:673-82. doi: 10.1161/CIRCULATIONAHA.113.003026

30. Barker AJ, Markl M. The role of hemodynamics in bicuspid aortic valve disease. Eur J Cardiothorac Surg. (2011) 39:805-16. doi: 10.1016/j.ejcts.2011.01.006

31. Hope MD, Hope TA, Crook SE, Ordovas KG, Urbania TH, Alley MT, et al. $4 \mathrm{D}$ flow CMR in assessment of valve-related ascending aortic disease. JACC Cardiovasc Imaging (2011) 4:781-7. doi: 10.1016/j.jcmg.2011.05.004

32. Bissell MM, Hess AT, Glaze SJ, Pitcher A, Robson MD, Barker AJ, et al. Cusp fusion pattern in bicuspid aortic valve disease predicts severity of aortic flow abnormalities. J Cardiovas Mag Reson. (2013) 15(Suppl 1): O96. doi: 10.1186/1532-429X-15-S1-O69

33. Sievers $\mathrm{HH}, \mathrm{Schmidtke}$ C. A classification system for the bicuspid aortic valve from 304 surgical specimens. J Thorac Cardiovasc Surg. (2007) 133:1226-33. doi: 10.1016/j.jtcvs.2007.01.039

34. Yousef A, Simard T, Webb J, Rodés-Cabau J, Costopoulos C, Kochman J, et al. Transcatheter aortic valve implantation in patients with bicuspid aortic valve: a patient level multi-center analysis. Int J Cardiol. (2015) 189:282-8. doi: 10.1016/j.ijcard.2015.04.066

35. Kochman J, Huczek Z, Scisło P, Dabrowski M, Chmielak Z, Szymanski P, et al. Comparison of one-and 12-month outcomes of transcatheter aortic valve replacement in patients with severely stenotic bicuspid versus tricuspid aortic valves (results from a multicenter registry). Am J Cardiol. (2014) 114:757-62. doi: 10.1016/j.amjcard.2014.05.063

36. Kodali SK, Williams MR, Smith CR, Svensson LG, Webb JG, Makkar RR, et al. Two-year outcomes after transcatheter or surgical aortic-valve replacement. $N$ Engl J Med. (2012) 366:1686-95. doi: 10.1056/NEJMoa1200384

37. Abdel-Wahab M, Mehilli J, Frerker C, Neumann FJ, Kurz T, Tölg R, et al. Comparison of balloon-expandable vs self-expandable valves in patients undergoing transcatheter aortic valve replacement: the CHOICE randomized clinical trial. JAMA (2014) 311:1503-14. doi: 10.1001/jama.2014.3316

38. Yoon SH, Lefèvre T, Ahn JM, Perlman GY, Dvir D, Latib A, et al. Transcatheter aortic valve replacement with early-and new-generation devices in bicuspid aortic valve stenosis. J Am Coll Cardiol. (2016) 68:1195-205. doi: 10.1016/j.jacc.2016.06.041

39. Yang TH, Webb JG, Blanke P, Dvir D, Hansson NC, Nørgaard BL, et al. Incidence and severity of paravalvular aortic regurgitation with multidetector computed tomography nominal area oversizing or undersizing after transcatheter heart valve replacement with the Sapien 3: a comparison with the Sapien, XT. JACC Cardiovasc Interv. (2015) 8:462-71. doi: 10.1016/j.jcin.2014.10.014

40. Tan JS, Leipsic J, Perlman G, Stub D, Dvir D, Hansson NC, et al. A strategy of underexpansion and ad hoc post-dilation of balloonexpandable transcatheter aortic valves in patients at risk of annular injury: favorable mid-term outcomes. JACC Cardiovasc Interv. (2015) 8:1727-32. doi: 10.1016/j.jcin.2015.08.011

41. Khatri PJ, Webb JG, Rodés-Cabau J, Fremes SE, Ruel M, Lau K, et al. Adverse effects associated with transcatheter aortic valve implantation: a meta-analysis of contemporary studies. Ann Intern Med. (2013) 158:35-46. doi: 10.7326/0003-4819-158-1-201301010-00007
42. Siontis GC, Jüni P, Pilgrim T, Stortecky S, Büllesfeld L, Meier B, et al. Predictors of permanent pacemaker implantation in patients with severe aortic stenosis undergoing TAVR: a meta-analysis. J Am Coll Cardiol. (2014) 64:129-40. doi: 10.1016/j.jacc.2014.04.033

43. Urena M, Rodes-Cabau J. Managing heart block after transcatheter aortic valve implantation: from monitoring to device selection and pacemaker indications. Eurointervention (2015) 11:W101-5. doi: 10.4244/EIJV11SWA30

44. Mauri V, Reimann A, Stern D, Scherner M, Kuhn E, Rudolph V, et al. Predictors of permanent pacemaker implantation after transcatheter aortic valve replacement with the SAPIEN 3. JACC Cardiovasc Interv. (2016) 9:22009. doi: 10.1016/j.jcin.2016.08.034

45. Urena M, Rodés-Cabau J. Conduction abnormalities. JACC Cardiovasc Interv. (2016) 21:2217-9. doi: 10.1016/j.jcin.2016.09.040

46. Guyton RA, Padala M. Transcatheter aortic valve replacement in bicuspid aortic stenosis: early success but concerning red flags. JACC Cardiovasc Interv. (2016) 9:825-7. doi: 10.1016/j.jcin.2016.02.042

47. Eltchaninoff H, Prat A, Gilard M, Leguerrier A, Blanchard D, Fournial G, et al. Transcatheter aortic valve implantation: early results of the FRANCE (FRench Aortic National CoreValve and Edwards) registry. Eur Heart J. (2010) 32:191-7. doi: 10.1093/eurheartj/ehq261

48. Linke A, Gerckens U, Wenaweser P, Tamburino C, Bosmans J, Brecker S, et al. Treatment of high risk aortic stenosis patients with transcatheter medtronic corevalve implantation: results from the international multi-center advance study. J Am Coll Cardiol. (2012) 59:E8. doi: 10.1016/S0735-1097(12)60009-6

49. Rodés-Cabau J, Webb JG, Cheung A, Ye J, Dumont E, Feindel CM, et al. Transcatheter aortic valve implantation for the treatment of severe symptomatic aortic stenosis in patients at very high or prohibitive surgical risk: acute and late outcomes of the multicenter Canadian experience. J Am Coll Cardiol. (2010) 55:1080-90. doi: 10.1016/j.jacc.2009.12.014

50. Thomas M, Schymik G, Walther T, Himbert D, Lefèvre T, Treede H, et al. Thirty-day results of the SAPIEN aortic Bioprosthesis European Outcome (SOURCE) Registry: a European registry of transcatheter aortic valve implantation using the Edwards SAPIEN valve. Circulation (2010) 122:62-9. doi: 10.1161/CIRCULATIONAHA.109.907402

51. Vahanian A. (ed.). Thirty-day outcomes in a 2700 patient international clinical registry with a second generation balloon expandable transcatheter heart valve using multiple access techniques. In: Euro-PCR Conference. Paris (2012).

52. Zahn R, Gerckens U, Grube E, Linke A, Sievert H, Eggebrecht H, et al. Transcatheter aortic valve implantation: first results from a multi-centre realworld registry. Eur Heart J. (2010) 32:198-204. doi: 10.1093/eurheartj/ehq339

53. Ribeiro HB, Nombela-Franco L, Urena M, Mok M, Pasian S, Doyle $\mathrm{D}$, et al. Coronary obstruction following transcatheter aortic valve implantation: a systematic review. JACC Cardiovasc Interv. (2013) 6:452-61. doi: 10.1016/j.jcin.2012.11.014

54. Jabbour RJ, Tanaka A, Finkelstein A, Mack M, Tamburino C, Van Mieghem N, et al. Delayed coronary obstruction after transcatheter aortic valve replacement. J Am Coll Cardiol. (2018) 71:1513-24. doi: 10.1016/j.jacc.2018.01.066

55. Gilard M, Eltchaninoff H, Iung B, Donzeau-Gouge P, Chevreul K, Fajadet J, et al. Registry of transcatheter aortic-valve implantation in high-risk patients. $N$ Engl J Med. (2012) 366:1705-15. doi: 10.1056/NEJMoa1114705

56. Kodali S, Pibarot P, Douglas PS, Williams M, Xu K, Thourani V, et al. Paravalvular regurgitation after transcatheter aortic valve replacement with the Edwards sapien valve in the PARTNER trial: characterizing patients and impact on outcomes. Eur Heart J. (2014) 36:449-56. doi: 10.1093/eurheartj/ehu384

57. Abdel-Wahab M, Zahn R, Horack M, Gerckens U, Schuler G, Sievert $\mathrm{H}$, et al. Aortic regurgitation after transcatheter aortic valve implantation: incidence and early outcome. Results from the German transcatheter aortic valve interventions registry. Heart (2011) 97:899-906. doi: $10.1136 /$ hrt.2010.217158.

58. Amat-Santos IJ, Dahou A, Webb J, Dvir D, Dumesnil JG, Allende R, et al. Comparison of hemodynamic performance of the balloon-expandable SAPIEN 3 versus SAPIEN XT transcatheter valve. Am J Cardiol. (2014) 114:1075-82. doi: 10.1016/j.amjcard.2014.07.019

59. Husser O, Pellegrini C, Kessler T, Burgdorf C, Thaller H, Mayr NP, et al. Outcomes after transcatheter aortic valve replacement using a novel 
balloon-expandable transcatheter heart valve: a single-center experience. JACC Cardiovasc Interv. (2015) 8:1809-16. doi: 10.1016/j.jcin.2015.08.014

60. Murray MI, Geis N, Pleger ST, Kallenbach K, Katus HA, Bekeredjian R, et al. First experience with the new generation Edwards Sapien 3 aortic bioprosthesis: procedural results and short term outcome. J Interv Cardiol. (2015) 28:109-16. doi: 10.1111/joic.12182

61. Webb J, Gerosa G, Lefèvre T, Leipsic J, Spence M, Thomas M, et al. Multicenter evaluation of a next-generation balloon-expandable transcatheter aortic valve. J Am Coll Cardiol. (2014) 64:2235-43. doi: 10.1016/j.jacc.2014.09.026

62. Meredith Am IT, Walters DL, Dumonteil N, Worthley SG, Tchétché D, Manoharan G, et al. Transcatheter aortic valve replacement for severe symptomatic aortic stenosis using a repositionable valve system: 30-day primary endpoint results from the REPRISE II study. J Am Coll Cardiol. (2014) 64:1339-48. doi: 10.1016/j.jacc.2014.05.067

63. Perlman GY, Blanke P, Webb JG. Transcatheter aortic valve implantation in bicuspid aortic valve stenosis. Eurointervention (2016) 12:Y42-5. doi: 10.4244/EIJV12SYA10

64. Philip F, Faza NN, Schoenhagen P, Desai MY, Tuzcu EM, Svensson LG, et al. Aortic annulus and root characteristics in severe aortic stenosis due to bicuspid aortic valve and tricuspid aortic valves: implications for transcatheter aortic valve therapies. Catheter Cardiovasc Interv. (2015) 86:E88-98. doi: $10.1002 / \mathrm{ccd} .25948$

65. Al Emam AR, Chamsi-Pasha M, Pavlides G. Ostial coronary occlusion during TAVR in bicuspid aortic valve, should we redefine what is a safe ostial height? Int J Cardiol. (2016) 212:288-9. doi: 10.1016/j.ijcard.2016.03.100

66. Himbert D, Pontnau F, Messika-Zeitoun D, Descoutures F, Detaint D, Cueff $\mathrm{C}$, et al. Feasibility and outcomes of transcatheter aortic valve implantation in high-risk patients with stenotic bicuspid aortic valves. Am J Cardiol. (2012) 110:877-83. doi: 10.1016/j.amjcard.2012.04.064

67. Hayashida K, Bouvier E, Lefevre T, Chevalier B, Hovasse T, Romano $\mathrm{M}$, et al. Transcatheter aortic valve implantation for patients with severe bicuspid aortic valve stenosis. Circ Cardiovasc Interv. (2013) 6:284-91. doi: 10.1161/CIRCINTERVENTIONS.112.000084

68. Frangieh AH, Kasel AM. TAVI in bicuspid aortic valves 'made easy'. Eur Heart J. (2017) 38:1177-81. doi: 10.1093/eurheartj/ehx167

69. Popma JJ, Ramadan R. CT imaging of bicuspid aortic valve disease for TAVR. JACC Cardiovasc Imaging (2016) 9:1159-63. doi: 10.1016/j.jcmg.2016.02.028
70. Xie X, Shi X, Xun X, Rao L. Efficacy and safety of transcatheter aortic valve implantation for bicuspid aortic valves: a systematic review and metaanalysis. Ann Thorac Cardiovasc Surg. (2016) 22:203-15. doi: 10.5761/atcs.ra. 16-00032

71. Shivaraju A, Thilo C, Ott I, Mayr PN, Schunkert H, von Scheidt W, et al. Tools and Techniques - Clinical: Fluoroscopic balloon sizing of the aortic annulus before transcatheter aortic valve replacement (TAVR) - follow the "right cusp rule". Eurointervention (2015) 11:840-2. doi: 10.4244/EIJV11I7A170

72. Kasel AM, Cassese S, Leber AW, von Scheidt W, Kastrati A. Fluoroscopyguided aortic root imaging for TAVR. JACC Cardiovasc Imaging (2013) 6:274-5. doi: 10.1016/j.jcmg.2012.06.014

73. Shivaraju A, Ott I, Cassese S, Bourier F, Kastrati A, Kasel AM, et al. Fluoroscopic calcification-guided optimal deployment projection during transcatheter aortic valve replacement-"The eye of the pigtail."(Follow the right cusp rule-Part II). Catheter Cardiovasc Interv (2016) 87:996-8. doi: $10.1002 / \mathrm{ccd} .25929$

74. Tay E, Singh D, Kong WK, Jimmy KF. Hybrid technique to bail out an unsuccessful transfemoral TAVR attempt. HonAsiaIntervention (2018) 4:38-40, doi: 10.4244/AIJ-D-17-00032

75. Rodríguez-Olivares R, Robert-Jan Van Geuns M, Peter De Jong M, Van Mieghem NM, De Jaegere P. How should I treat a patient with a stenosed bicuspid aortic valve and an unexpected finding during TAVI? Eurointervention (2014) 9:1474-7. doi: 10.4244/EIJV9I12A246

76. Zhao ZG, Jilaihawi H, Feng Y, Chen M. Transcatheter aortic valve implantation in bicuspid anatomy. Nat Rev Cardiol. (2015) 12:123-8. doi: 10.1038/nrcardio.2014.161

Conflict of Interest Statement: The authors declare that the research was conducted in the absence of any commercial or financial relationships that could be construed as a potential conflict of interest.

Copyright $(02018$ Das and Puri. This is an open-access article distributed under the terms of the Creative Commons Attribution License (CC BY). The use, distribution or reproduction in other forums is permitted, provided the original author(s) and the copyright owner(s) are credited and that the original publication in this journal is cited, in accordance with accepted academic practice. No use, distribution or reproduction is permitted which does not comply with these terms. 